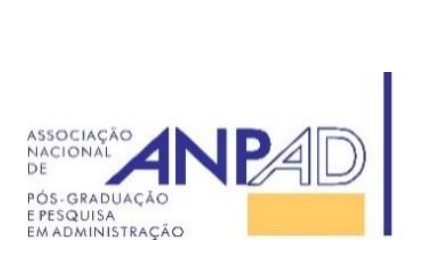

Disponível em

http://www.anpad.org.br/rac

RAC, Rio de Janeiro, v. 20, n. 1, art. 6, pp. 106-130, Jan./Fev. 2016

http://dx.doi.org/10.1590/1982-7849rac2016140095

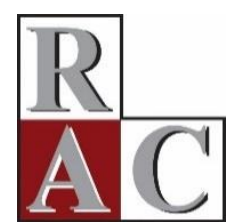

$(\mathrm{Cc}) \mathrm{BY}$

\title{
Há Fatores Não Econômicos na Formação do Preço de Imóveis?
}

Are There Non-economic Factors in Real-estate Pricing?

Lincoln Brando ${ }^{1}$

Claudio Henrique Barbedo ${ }^{1}$

Faculdades IBMEC-RJ ${ }^{1}$ 


\title{
Resumo
}

O presente trabalho procura investigar a existência de um fator explicativo para a evolução do preço de imóveis residenciais, em particular nas cidades do Rio de Janeiro e de São Paulo. Procura-se modelar o comportamento desses preços em função de variáveis explicativas de demanda e oferta, e avaliar em que medida variáveis dos tipos comportamentais e econômicas ajudam a explicar o movimento de preços. Os resultados sugerem que o preço de imóveis é influenciado por determinantes não usuais à luz da teoria econômica, como a variação do preço no mês anterior, uma medida de expectativa, e a performance da Bolsa.

Palavras-chave: finanças comportamentais; mercado imobiliário; boom imobiliário.

\begin{abstract}
This work aims to identify the existence of explanatory factors for real-estate pricing, focusing on homes in the Rio de Janeiro e São Paulo markets. We tried to model prices as a function of supply and demand factors, and then proceed to evaluate to what extent adding behavioral and economic factors helps improve explanation of price movements. The results suggest that home pricing is explained by variables not usually used in economic theory, such as the previous month's price, expectation measurement and stock exchange performance.
\end{abstract}

Key words: behavioral finance; housing market; housing bubble. 


\section{Introdução}

Segundo Mayer (2011), o ciclo imobiliário global, que se iniciou em fins dos anos 90, foi o mais impressionante de que se tem registro, por dois aspectos inéditos até então: a magnitude das altas de preço, e a abrangência do movimento sincronizado em diversos países e, sobretudo, em economias centrais.

A Figura 1, com dados compilados pelo The Economist, cobre o período do primeiro trimestre de 1995 ao terceiro trimestre de 2013. Observa-se o ciclo completo, com a ascensão, o pico, e a queda de preços. Os índices apresentados são de altas nominais para EUA, França, Itália, Dinamarca, Irlanda, e Espanha. Passados alguns anos de queda do mercado, em muitos países, o preço real atual encontra-se próximo ao patamar de início da década de 2000.

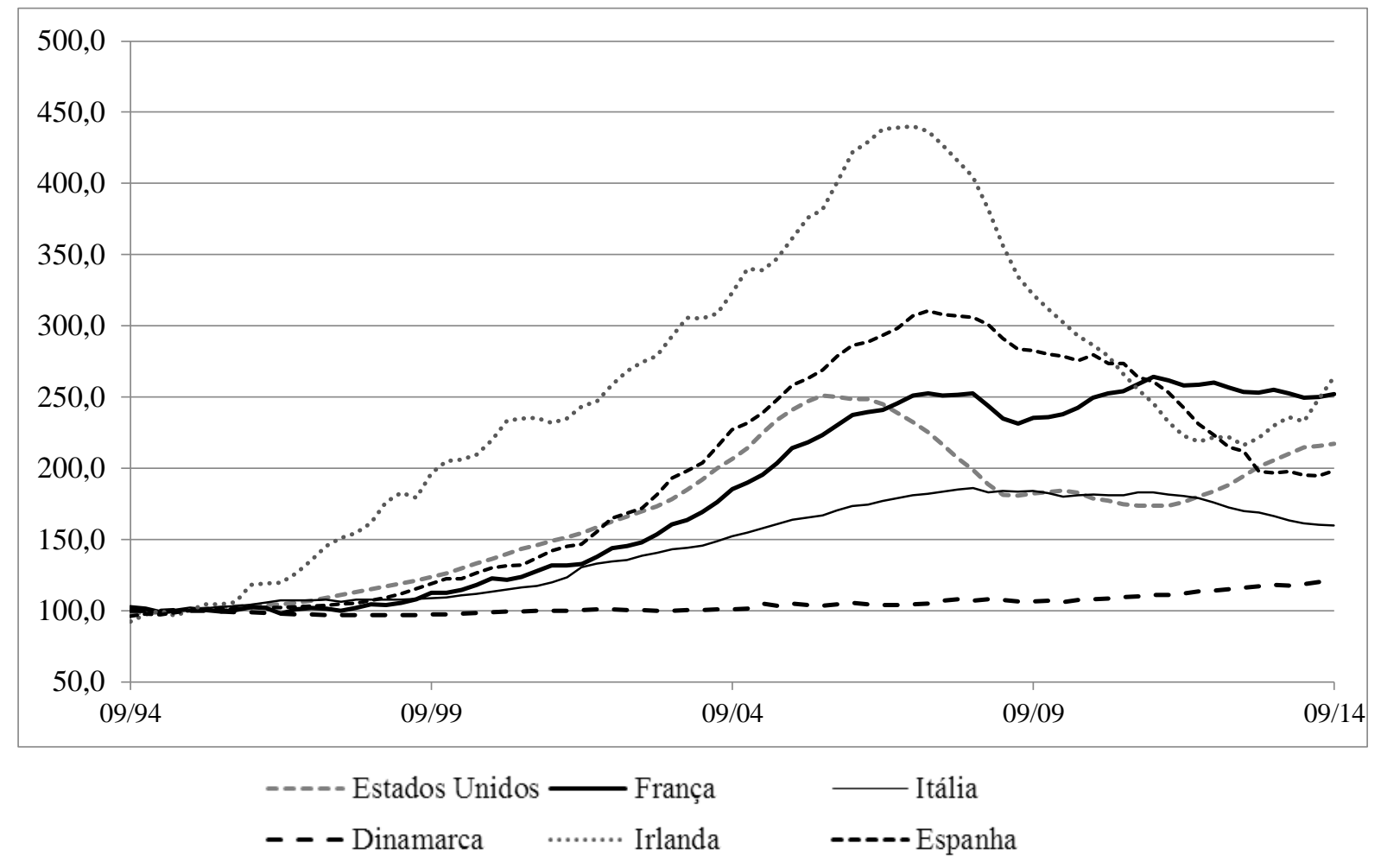

Figura 1. Índice de Preço de Imóveis em Diversos Países

Fonte: Adaptado de The Economist. (2015, October 7). Global house prices. Recuperado de http://www.economist.com/blogs/dailychart/2011/11/global-house-prices

No que diz respeito aos países ditos em desenvolvimento (ou periféricos), o ciclo de alta acontece com defasagem de 6 a 10 anos em relação às economias centrais segundo o Bank of International Settlements (BIS). Em muitos casos, o ciclo de alta teve início no momento em que o mercado de imóveis dos países ricos enfrentava o início da queda de preços (2007/2009). A Figura 2, do relatório de 2012 do BIS, apresenta o comparativo entre o preço deflacionado de algumas capitais de países latino-americanos. 

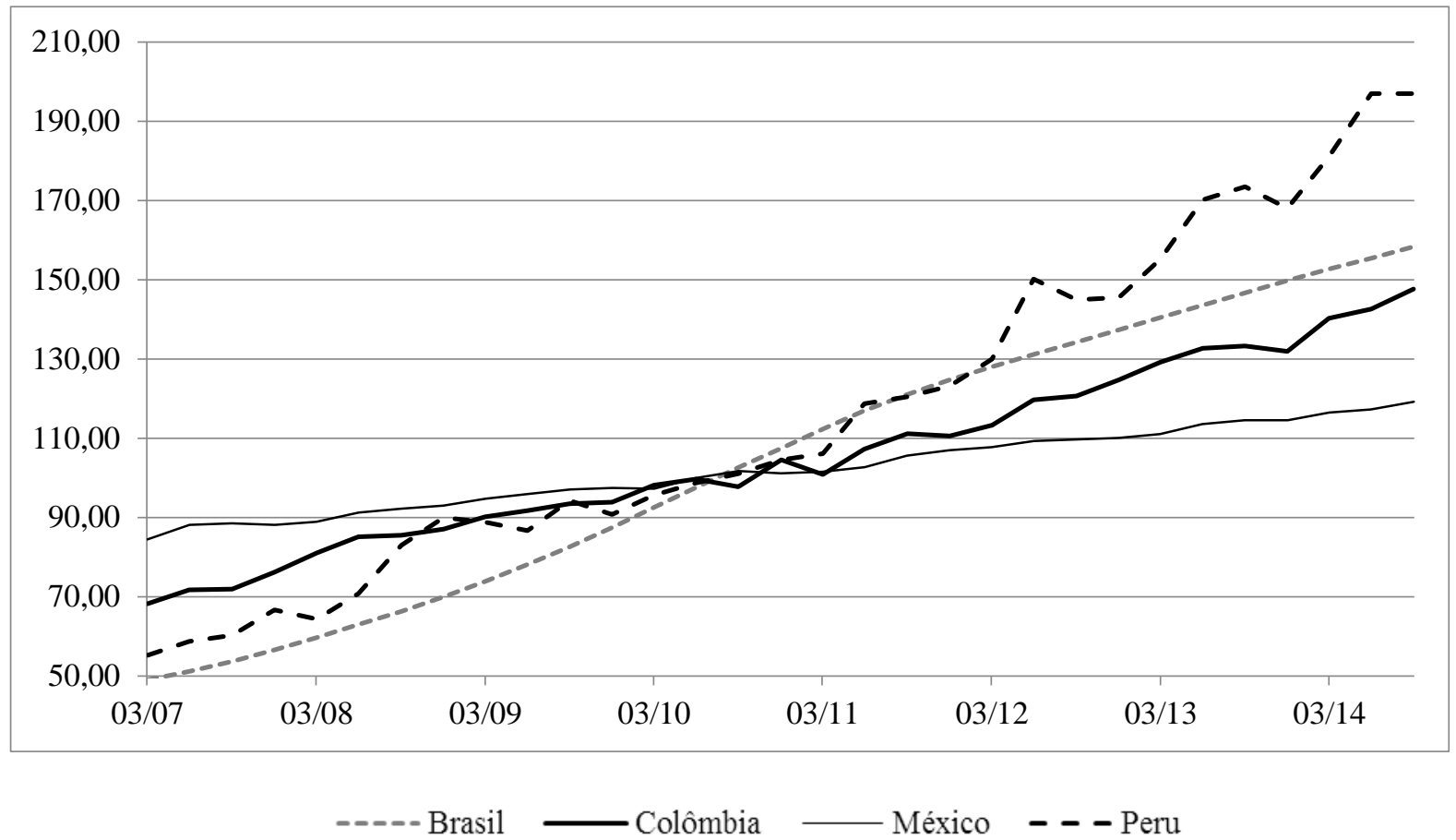

Figura 2. Comparativo da Evolução de Imóveis Residenciais na América Latina

Fonte: Adaptado de Bank for International Settlements. (2015, September 13). Residential property price statistics. Recuperado de http://www.bis.org/statistics/pp.htm

À exceção do México, a Figura 2 aponta aumentos expressivos em um curto intervalo de tempo. Do ponto de vista econômico, essa abrupta elevação merece destaque, dado que os imóveis constituem a maior parcela do patrimônio das famílias. Com isso, Krugman (2009) afirma que movimentos no preço de imóveis produzem efeitos significativos na economia de um país, seja no Produto Interno Bruto, seja no nível de emprego da construção civil, seja no orçamento ou no endividamento das famílias. Além disso, dada a crescente securitização dos financiamentos, bancos também passaram a ficar crescentemente expostos a oscilações no preço de imóveis.

Uma questão recorrente nos ciclos imobiliários mais agudos ao redor do mundo, e que se aplica ao caso brasileiro, é saber em que medida o movimento de preços de imóveis é justificado por fundamentos econômicos. Case e Shiller $(1988,2003)$ são os primeiros a pesquisar se os preços dos imóveis podem ser atribuídos a fatores que repousam em vieses de comportamento individual ou na psicologia de massas. Nesse sentido, o objetivo do trabalho é verificar se há um fator de natureza comportamental ou econômico que possa ter influenciado o movimento de preços dos mercados do Rio de Janeiro e São Paulo. A contribuição deste trabalho para a literatura é verificar fatores de influência do preço de imóveis através de índices usualmente utilizados na literatura brasileira e do índice criado nesse trabalho, desde 1999, em relação a fundamentos econômicos, também denominados de racionais, ou psicológicos, também denominados de comportamentais.

Além da presente introdução, o artigo está dividido em mais cinco seções. A próxima seção aborda a revisão de literatura. A seguir, apresentam-se as variáveis do mercado imobiliário brasileiro, a abordagem econométrica adotada e os dados utilizados nos modelos econométricos. Por fim, os resultados são discutidos e apresentam-se as conclusões.

\section{Revisão de Literatura}

Na literatura internacional, há uma crescente sinalização da importância de se verificar se o movimento de preços de imóveis é justificado por fundamentos econômicos ou por movimentos 
comportamentais. De acordo com Goodman e Thibodeau (2008), e Antipa e Lecat (2009), a teoria econômica básica indica que o preço de imóveis de longo prazo é determinado pelo equilíbrio entre, por um lado, renda, variável demográfica, taxa de juros da economia, impostos e condições de crédito e, por outro, estoque total de imóveis, custo de terrenos e de construção e limitações estruturais da oferta.

Sob o ponto de vista das Finanças Comportamentais, da mesma forma que a teoria econômica, acredita-se que preços são determinados por fundamentos (De Bondt \& Thaler, 1985). No entanto, advoga-se a tese de que a não racionalidade no comportamento dos agentes e das características de mercados voláteis desempenham papel relevante, sobretudo, para explicar os ciclos agudos de boom (elevação) e bust (estouro) do preço. Glaeser, Gyourko e Saiz (2008) argumentam que o mercado imobiliário tem características de mercados voláteis. Nesse tipo de mercado, preços frequentemente podem divergir dos fundamentos, dado os elevados custos de transação, a baixa participação de instrumentos derivativos para prover seguros contra quedas, e as dificílimas oportunidades de arbitragem. Glaeser e Gyourko (2006) apontam outros fatos estilizados sobre o mercado de imóveis, como o fato de as taxas de variação do preço serem serialmente correlacionadas (a formação de expectativas de preço futuro dá-se com o preço passado recente) e o fato de existir tendência de reversão à média após períodos mais longos. Essas características sugerem fortemente o uso de variáveis comportamentais nas abordagens econométricas.

Mayer e Sinai (2007) avaliam o peso relativo de fundamentos econômicos e psicológicos para explicar a dinâmica de preços nos EUA. Os autores avaliam o impacto de dois componentes comportamentais desenvolvidos pela literatura: o backward looking, ou seja, a elevada autocorrelação do preço de imóveis, justificada pela ideia de que, em ciclos de alta, a expectativa de crescimento do preço baseia-se no crescimento anterior, e a ilusão monetária, ou seja, o conceito de que os agentes, em um cenário de queda de inflação, acessam o crédito para adquirir imóveis estimulados pela redução nas taxas de juros nominais, mas deixam de considerar o efeito futuro de redução de aluguéis em suas avaliações. Hott (2012) pesquisa a possibilidade do efeito manada explicar os desvios de preço de imóveis em relação a seus fundamentos. Os resultados indicam uma força explicativa significativa para alguns países, mas pouco relevante em outros. Hwang e Quigley (2006) verificam que preços de sua amostra estão relacionados apenas a variáveis econômicas e são positivamente correlacionados a renda e ao produto, além de negativamente correlacionados a taxa de juros. No Brasil, ainda não há literatura específica sobre fatores comportamentais e boa parte das pesquisas tenta identificar as variáveis econômicas que se relacionam ao preço. Nesse sentido, Carvalho (2012) afirma que, desde novembro de 2010, há um descolamento entre preço do metro quadrado e retorno de aluguel na cidade de São Paulo. Mendonça e Sachsida (2012) montam uma regressão do preço de imóveis em função do aluguel, da expectativa de preço futuro (proxy do ganho de capital) e da taxa de juros. Os autores concluem que há indícios de bolha imobiliária no Brasil, mas que os efeitos de um possível estouro seriam de impacto menor do que o ocorrido nos EUA e em alguns países europeus. Marçal, Gala e Mori (2012) testam a presença de bolha e afirmam que, embora não possa ser totalmente descartada, a hipótese mais provável é que o aumento dos preços de imóveis pode ter sido ocasionado por fatores normais ligados a excesso de demanda por imóveis. Oliveira e Almeida (2014) empregam testes de cointegração a partir de Case e Shiller (1988) para verificar desvios em relações de cointegração de variáveis. O objetivo dos autores é analisar o comportamento explosivo dos múltiplos Preço-Renda e Preço-Aluguel nos mercados imobiliários de Rio de Janeiro e São Paulo. Os autores concluem que a metodologia indica a existência de bolhas de preços nos dois mercados mais importantes do país.

\section{Variáveis do Mercado Imobiliário Brasileiro}

Dentre os argumentos dos que defendem que a subida dos preços no mercado imobiliário nos trouxe a um novo paradigma de preços, com suficientes elementos estruturais para se manter, destacase o crescimento de renda e melhorias nas condições de crédito responder pelo aumento de capacidade de compra na demanda; o descompasso entre oferta e demanda; limitações de espaço nas áreas nobres; e o retorno do aluguel em linha com o patamar da taxa de juros referência da economia. Dentre os 
argumentos que apontam sintomas de desequilíbrio no comportamento do preço, a agência classificadora de risco Fitch Ratings (2012) aponta o fato dos preços dos imóveis crescerem bem acima da renda média e a existência de demanda por investidores nacionais e estrangeiros para auferir ganho de capital por conta dos megaeventos sediados no Brasil. Portanto, este conceito de boom imobiliário pode ser caracterizado por variáveis, como volume de lançamentos, crédito e, de forma mais sensível, pela evolução do preço por metro quadrado.

O comportamento do preço, na segunda metade da década de 2000, vem sendo a característica mais destacada do boom imobiliário brasileiro, porém há uma forte limitação para obtenção de uma série histórica longa de preços de imóveis no Brasil. Para reverter esta situação, desde janeiro de 2008, a Fundação Instituto de Pesquisas Econômicas (FIPE), em parceria com o portal de anúncios ZAP Imóveis, passou a medir a evolução dos preços anunciados de venda nas cidades do Rio de Janeiro e de São Paulo. Mais tarde, outras capitais importantes foram adicionadas. Essa medida de preços, malgrado não espelhar adequadamente o preço em que efetivamente os negócios são fechados, é uma métrica importante no mercado.

A Figura 3 mostra a significativa elevação dos preços de imóveis anunciados para São Paulo e Rio, medidos em Reais nominais, em relação a diversos índices. O preço dos imóveis em São Paulo e Rio chegam, a março de 2014 , com uma alta acumulada de $249,8 \%$ e $201,3 \%$, respectivamente, o que pode sinalizar um indício de desajustes nesse mercado. O cotejo da evolução dos preços de imóveis com a curva de custos de construção (Índice Nacional de Custo da Construção [INCC]) mostra descolamentos de magnitude elevada, com os preços subindo, em termos reais, algo entre $200 \%$ e $250 \%$ em 6 anos, enquanto o indicador dos custos setoriais (INCC) subiu apenas 61\%, no mesmo período. No que diz respeito à análise preço e renda, a magnitude do gap é ainda mais impressionante: a renda real per capita subiu $18 \%$ no período - um crescimento robusto para o período de 6 anos, mas bastante inferior à evolução dos preços de imóveis.

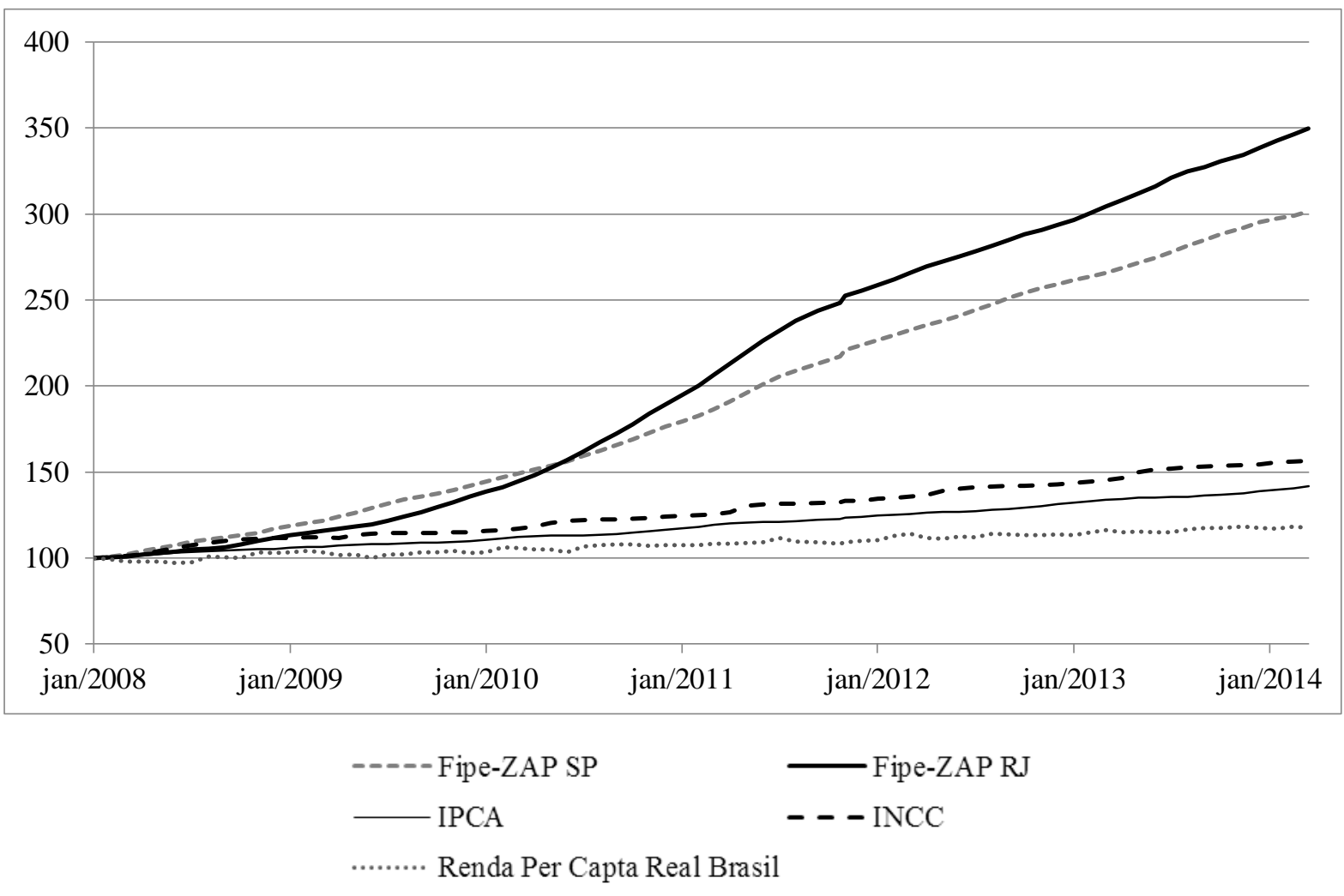

Figura 3. Evolução do FIPE-ZAP versus Diversos Índices

O Banco Central do Brasil divulga, desde 2001, um índice que vem sendo adotado como proxy para se medir a evolução dos preços de imóveis. Trata-se do índice de variação de garantias (IVG-R), 
que mede os valores de garantias (o próprio imóvel) dadas aos bancos para a tomada do financiamento imobiliário. A Figura 4 compara a evolução do IVG-R, medido a partir de março de 2001, com outros indicadores.

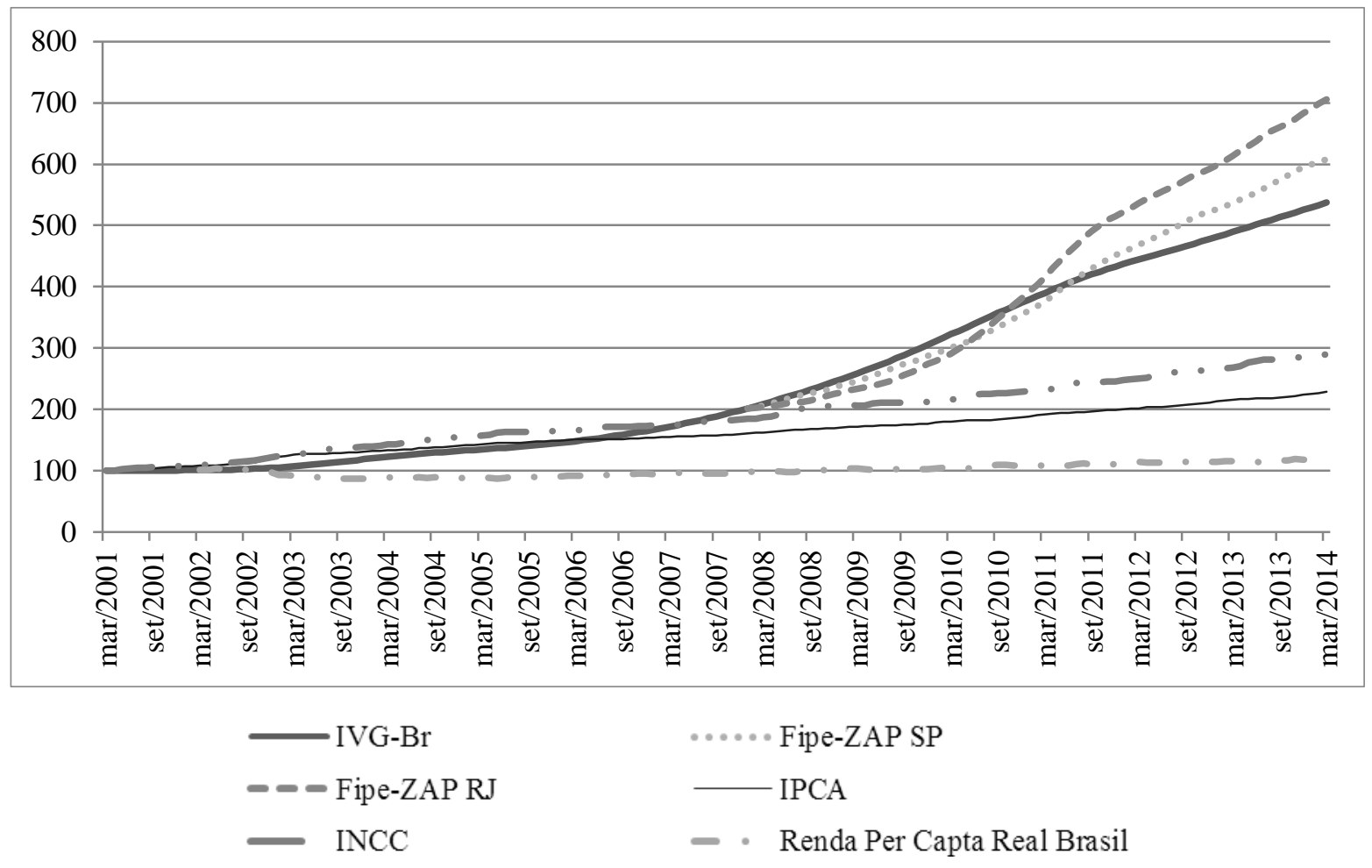

Figura 4. Evolução do IVG-R versus Diversos Índices

O IVG-R alinha-se aos indicadores Fipe-ZAP para as duas cidades, a partir de 2008. Expandindose o horizonte de análise até o ano 2001 (início da série IVG-R), confirma-se a sugestão de que um movimento agudo de elevação de preços surgiu na segunda metade da década passada, por volta de 2008. O avanço real acumulado da renda per capta das pessoas ocupadas para o período (série com início 2002) foi da ordem de 18\%. O aumento do IVG-R, deflacionado pelo Índice Nacional de Preços ao Consumidor Amplo (IPCA), para o período é da ordem de 309\%. Explicar o aumento dos preços de imóveis apenas pela ótica da renda é claramente insuficiente.

Por fim, no intuito de buscar dados de preços mais antigos, compila-se um índice composto de preços de imóveis do Rio de Janeiro a partir de dados publicados no caderno Morar Bem, do Jornal O Globo (1998-2014). Essas informações disponibilizadas pelo Jornal têm como fonte os anúncios de imóveis dos classificados e dados do Sindicato da Habitação do Rio de Janeiro (SECOVI-RJ) ${ }^{(1)}$. No intuito de suavizar a série, toma-se a média móvel de 3 meses, a valores nominais, com data de início em janeiro de 1999. Na Figura 5, a série Índice Composto Globo (linha tracejada) é comparada a outras séries de preços. 


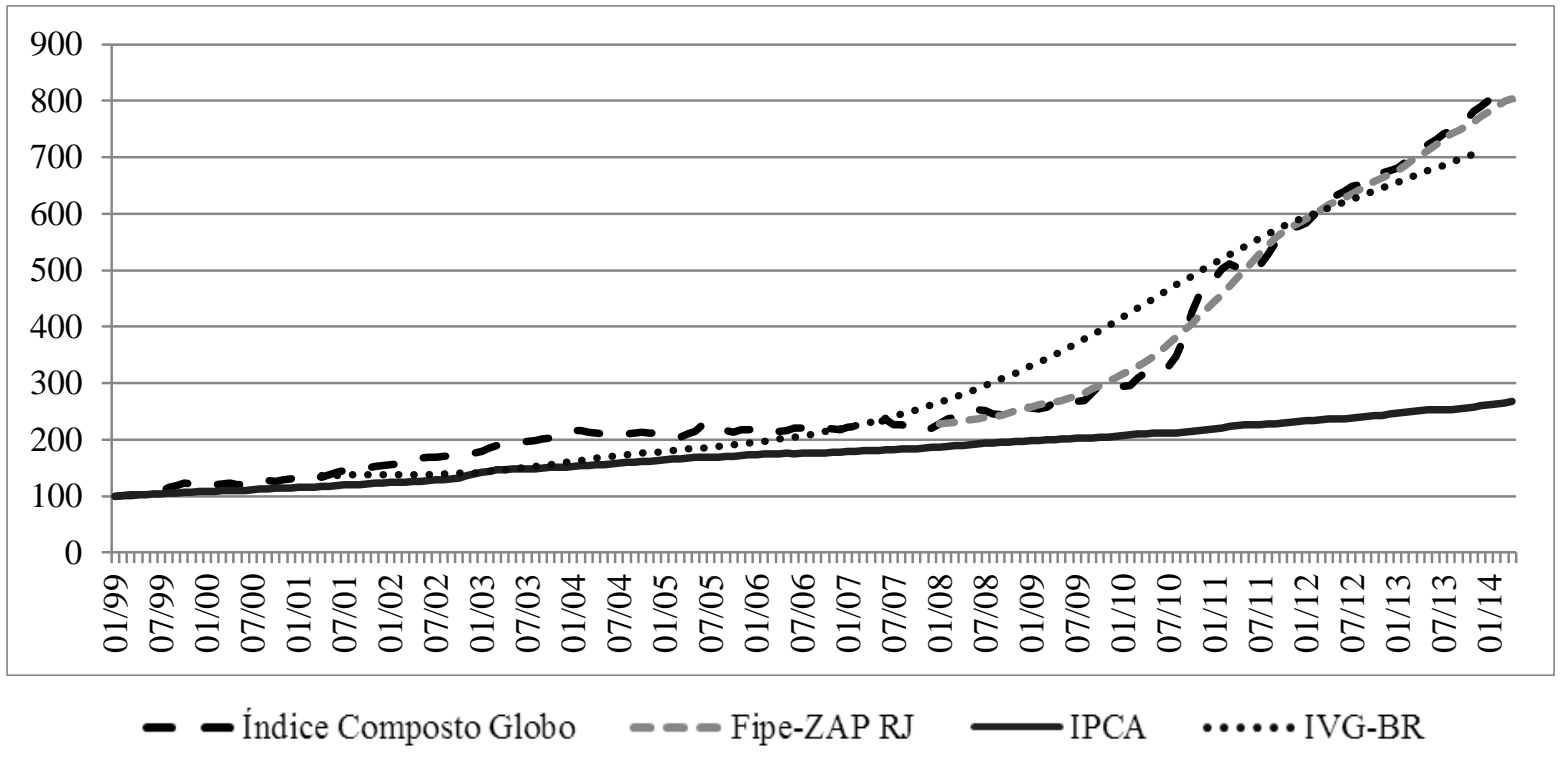

Figura 5. Evolução do Índice Composto Globo versus Diversos Índices

A aderência do Índice Composto Globo ao Fipe-ZAP RJ, a partir de 2008, sugere a consistência daquela série montada a partir de informações do jornal. Com isso, pode-se dividir o período analisado, de 1999 a 2014, em 3 partes. Na $1^{\text {a }}$ parte, de 1999 a 2003, o preço de imóveis do Rio de Janeiro caminha acima da inflação, tendo acumulado uma alta de 60 pontos percentuais acima do IPCA, em dezembro de 2003. Na $2^{\mathrm{a}}$ parte, de 2004 a 2007, os preços se estabilizam e chegam a perder para a inflação do período. A alta acumulada, em dezembro de 2007, desde o início da série (1999), chega a 34\% acima do IPCA. Na última parte, ocorreu o impressionante ciclo de alta de preços. Esse ciclo, de 2008 até 2014, é marcado por uma aceleração inicial no início de 2008, seguida por um estágio de aceleração aguda, a partir de 2009/2010.

Sob a ótica do crédito, medido pelos contratos firmados com recursos do Fundo de Garantia do Tempo de Serviço (FGTS) e da poupança e livres (Sistema Brasileiro de Poupança e Empréstimo [SBPE]), pode-se constatar que o movimento de financiamento de aquisição de imóveis na década passada supera em larga medida todo o registro pós 1995. A Figura 6 apresenta a quantidade de unidades imobiliárias financiadas (contratadas) anualmente desde $1994^{(2)}$.

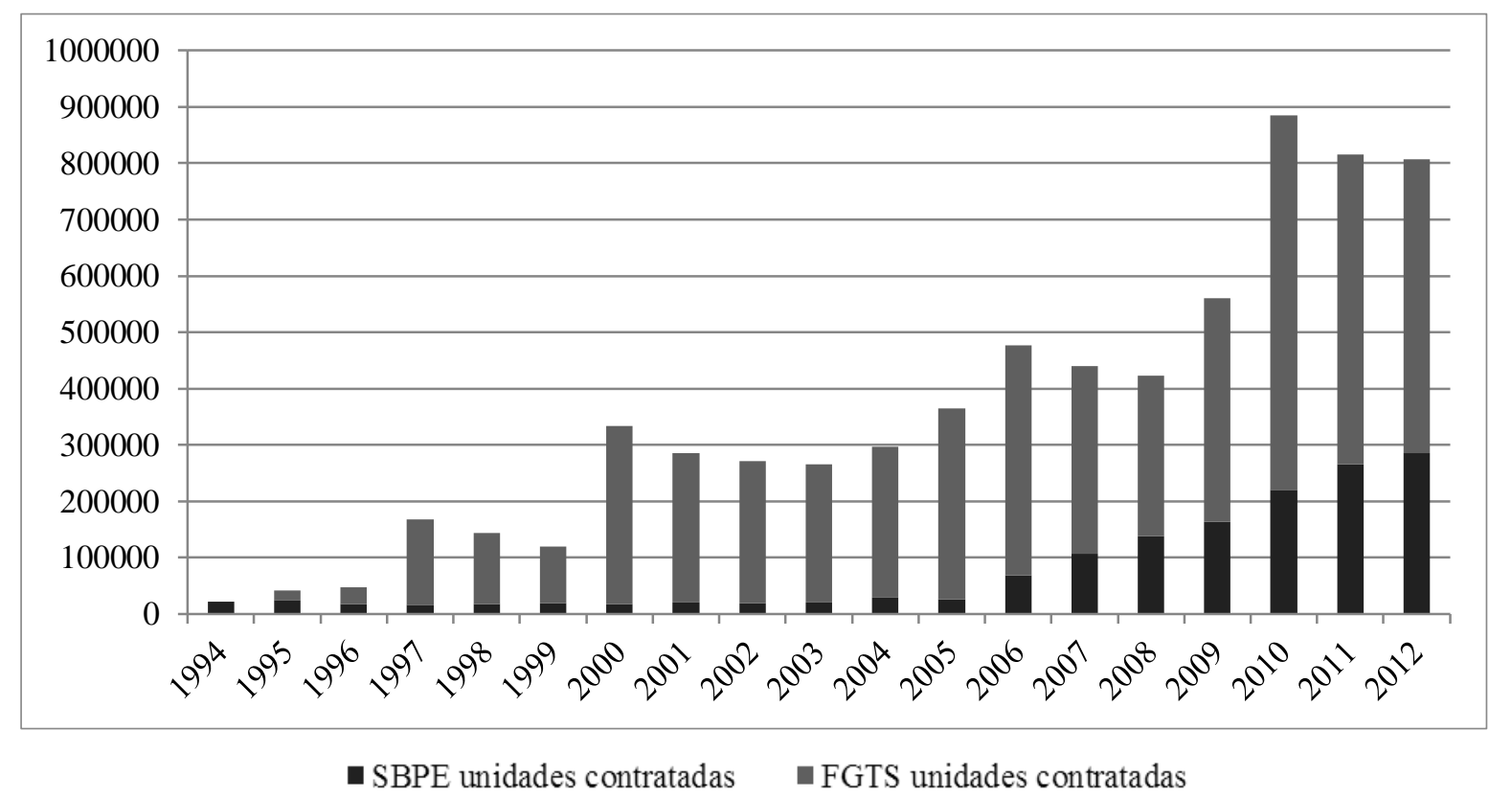

Figura 6. Unidades Contratadas Financiamento Imobiliário (Anual) 
A evolução dos lançamentos nas 2 principais cidades do país, na Figura 7, sugerem situações diferentes ${ }^{(3)}$. Com dados da cidade do Rio de Janeiro apenas a partir de 1994 (Associação de Dirigentes de Empresas do Mercado Imobiliário [ADEMI-RJ], n.d.), verifica-se um comportamento mais agudo do crescimento no volume de unidades residenciais lançadas, a partir de meados dos anos 2000. A curva de São Paulo, ainda que indique um patamar elevado de lançamentos a partir de 2007, apresenta crescimento menor do que os do Rio de Janeiro.

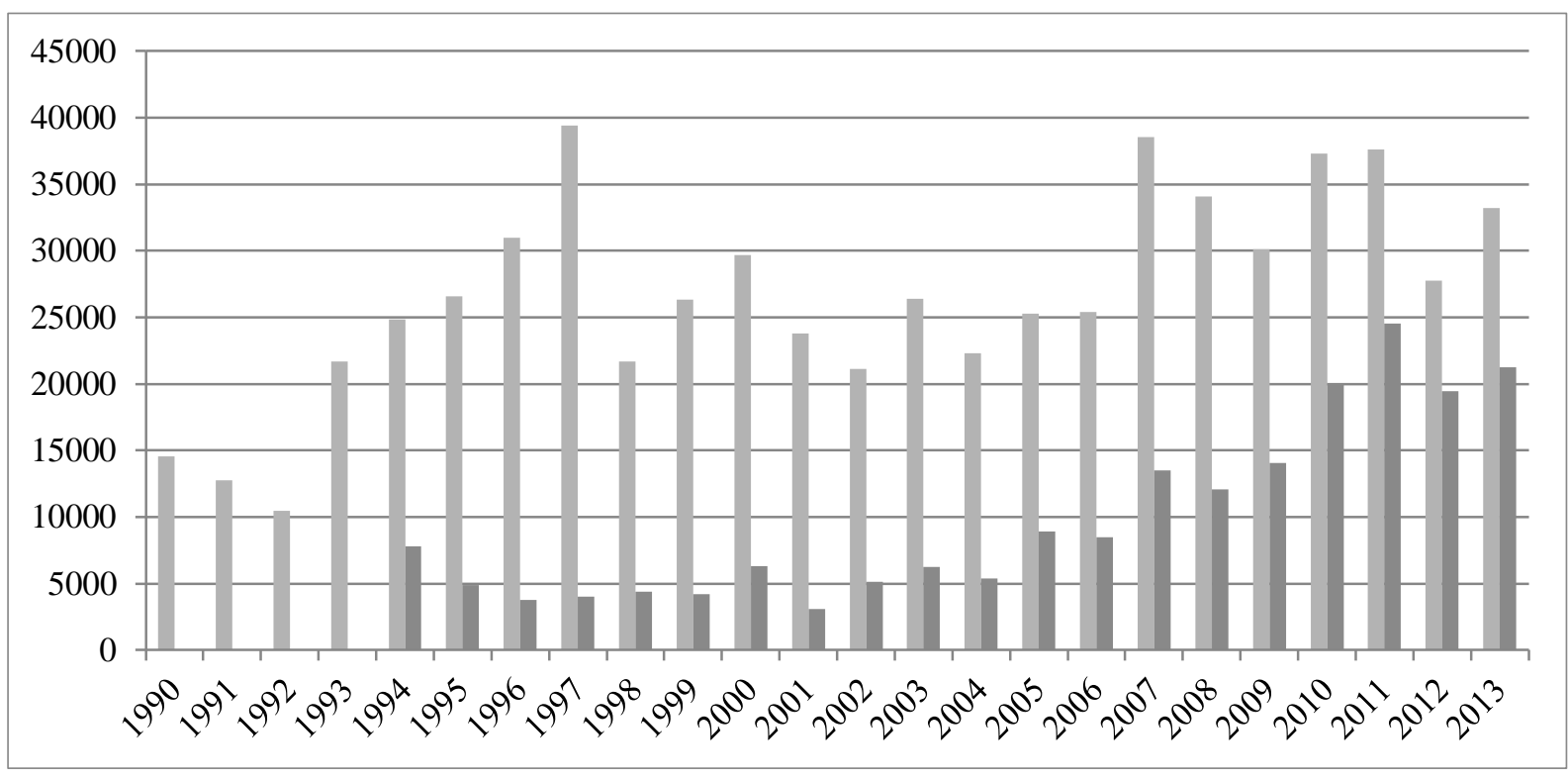

- Lançamentos SP $\quad$ Lançamentos RJ

Figura 7. Lançamentos Residenciais RJ e SP (Anual)

Apesar da relação empírica entre essas variáveis e o preço, a discussão acerca dos determinantes do preço de imóveis e de suas relações entre si não é pacífica. De acordo com Abelson, Joyeux, Milunovich e Chung (2005), a teoria econômica indica que o preço de imóveis no longo prazo é determinado por: (a) Renda; (b) Demografia; e (c) Elementos que compõem o chamado User Cost (custos de manutenção/depreciação, taxa de juros, expectativa de valorização do imóvel). Mas essa abordagem básica deixa de fora as interrelações entre o preço e os fatores de oferta. Gallin (2008) encontra evidências, com base em estudos econométricos com dados do mercado americano de 19702003, em que desvios na relação histórica Preço/Aluguel tendem a ser corrigidos - mas com uma defasagem longa, de 4 anos. O sentido mais provável para a correção, de acordo com modelo de longo prazo, é que os preços recuem para reequilibrar a relação com aluguel - e não o contrário, que alugueis subam o suficiente para restabelecer a relação Preço/Aluguel histórica. O uso mais sistematizado de ferramentas de finanças comportamentais aplicadas ao mercado de imóveis ganha relevância com Case e Shiller (1988), que notam o aspecto marcadamente autocorrelacionado do comportamento do preço de imóveis e sugerem contradição com a suposição de mercados eficientes.

\section{Metodologia e Dados}

Considerando a falta de consenso na literatura sobre modelo ou equação de relação de preço de imóveis, (Mayer \& Sinai, 2007). a metodologia seguirá duas abordagens.

Na primeira abordagem, utiliza-se uma regressão multivariada, tendo preço de imóveis (ou retorno) como variável dependente, e um conjunto de determinantes dado por fatores de demanda, fatores de oferta e fatores gerais. Os fatores de demanda estudados são: renda ou produto; condições do financiamento imobiliário; população ou outras variáveis demográficas e taxa de desemprego. Os fatores 
de oferta são: estoque de imóveis; quantidade de lançamentos; custos de construção e indicadores do nível de atividade da indústria de construção civil. Por fim, os fatores gerais são: IPCA e Taxa de juros da economia.

A regressão multivariada permite flexibilidade de especificação e simplicidade nas interpretações dos coeficientes. Entretanto, inferências adequadas sobre relações de causalidade entre as variáveis demandam o pressuposto da exogeneidade dos regressores, ou seja, a premissa de não correlação entre as variáveis explicativas e o termo de erro aleatório. A não verificação desse pressuposto é determinada, sobretudo, por variáveis omitidas. Para fazer face a esse problema, inserimos diferentes variáveis para medir o componente comportamental, lags dessas variáveis e variáveis de controle à regressão base, no intuito de aferir sua significância e a consistência do modelo.

Na segunda abordagem, adota-se um Modelo de Correção de Erros (MCE) em 2 estágios. Primeiramente, deriva-se uma equação de longo prazo que capture os determinantes mais essenciais do preço no longo prazo. A seguir, monta-se a equação de curto prazo em diferenças, com o termo de correção de erro (que é o resíduo da regressão de longo prazo com 1 defasagem), um termo com informação autoregressiva e ajustes parciais a fundamentos. Da mesma forma que na regressão multivariada, variáveis para medir componentes comportamentais serão adicionadas à equação de curto prazo para se medir sua significância.

\section{Base de dados}

A pesquisa de séries temporais mais longas para as variáveis do mercado imobiliário mostra-se um desafio no Brasil. Além da ausência generalizada dessas séries, as barreiras encontradas são desde descontinuidade metodológica, frequência insuficiente (dados anuais apenas), até abrangência geográfica inadequada.

Não obstante, busca-se obter as séries mais longas possíveis. Nos dados gerais da economia, as séries foram obtidas no Instituto Brasileiro de Geografia e Estatística (IBGE), no Instituto de Pesquisa Econômica Aplicada (IPEA), na Fundação Getulio Vargas (FGV) e no Banco Central do Brasil (BACEN), e, nos dados do mercado imobiliário, na ADEMI-RJ, no SECOVI-SP, na Associação Brasileira das Entidades de Crédito Imobiliário e Poupança (ABECIP) e na Câmara Brasileira da Indústria da Construção (CBIC).

\section{Dados gerais}

As fontes das séries de preços no Rio e em São Paulo são o FIPE-ZAP de 2008 a abril de 2014, e, no Brasil, o IVG-R (BACEN) de 2001 a abril de 2014. Ainda no Rio de Janeiro, o caderno Morar Bem, do Jornal O Globo, de 1999 a abril de $2014^{(4)}$. As séries de renda e população são do IBGE, as séries dos índices de preços (INCC e IPCA) são da FGV, as séries de crédito (unidades residenciais financiadas e contratadas, volume total $(\mathrm{R} \$)$ de operações de financiamento imobiliário e prazo médio do financiamento) são da ABECIP e do Banco Central, as séries de liquidez são do Banco Central, a série de ofertas (unidades lançadas, nível de atividade da construção civil Brasil, índice de vendas de material de construção civil e PIB construção civil) são do IBGE e as séries macroeconômicas (Produto Interno Bruto Brasil, Rio e São Paulo, Sistema Especial de Liquidação e de Custódia [SELIC] e taxa de desemprego) são do IBGE e do Banco Central ${ }^{(5)}$.

\section{Modelagem do componente comportamental}

Mayer e Sinai (2007) sugerem algumas abordagens para medir efeitos ad hoc em regressões. Em geral, após se estimar o modelo da equação base, adicionam-se variáveis para testar a significância do coeficiente estimado e o ajuste do novo modelo. A descrição das variáveis selecionadas encontra-se a seguir: 
Medida de backwards looking (expectativas adaptativas) - É sabido que backwards looking (autocorrelação) pode não significar irracionalidade. No entanto, é indício de fator comportamental na geração de expectativas dos agentes. O preço de imóveis tem característica inercial forte, e há indícios de que os agentes formem expectativas com base no preço passado, em detrimento das condições econômicas prospectivas.

Pode ser medido com a adição de 1 lag da variável dependente ao modelo de regressão.

Índices de confiança do consumidor - Fornecem uma medida geral de expectativa de consumidores quanto ao futuro da economia, e de suas finanças pessoais e familiares, de modo geral. Esse indicador pode capturar o ânimo dos compradores, no intuito de buscar correlações dessa medida com comportamento do preço de imóveis. As 3 séries selecionadas são o Índice de Confiança do Consumidor (ICC-FGV), medido pela FGV para o Brasil, o índice nacional de expectativas do consumidor (INEC), medido pela Confederação Nacional das Indústrias (CNI) para o conjunto de regiões metropolitanas do Brasil e o Índice de Expectativas do Consumidor (IEC), medido pela Fecomércio-SP para a região metropolitana de São Paulo.

IBOVESPA - A intenção é medir um possível efeito substituição entre bolsa de valores e mercado de imóveis. Esse comportamento não denota necessariamente um fator comportamental, mas, conforme Shiller (2007), é um potencial indicador de entusiasmo com o investimento imobiliário.

Dummies de Inovações - Inovações institucionais podem produzir pontos de rupturas em séries históricas. A intenção é medir o efeito produzido por eventos como a ampliação do limite do FGTS para enquadramento de financiamento; o advento das leis do inquilinato, alienação fiduciária e incorporação imobiliária; o lançamento do programa de incentivo à construção voltada à baixa renda (Programa Minha Casa Minha Vida). Novamente, não se trata aqui de medir efeito comportamental strictu sensu, mas uma medida para justificar a euforia excessiva de compradores.

Dummies comportamentais - Adicionam-se dummies para medir o impacto de: (a) realização da Copa do Mundo; (b) realização dos Jogos Olímpicos; (c) lançamento das UPPs no RJ; e (d) efeito das matérias de capa da revista The Economist com o Cristo Redentor. A data de início desta última dummy é agosto de 2009, mês da capa da revista The Economist que retrata o Cristo Redentor levantando voo, como se um foguete fosse. A data fim é julho de 2011, mês em que o Financial Times publica uma matéria especial com a manchete: Brasil, uma bicicleta difícil de pedalar.

\section{Resultados}

São testadas especificações básicas para as 4 variáveis dependentes, a saber: preços FIPE-ZAP RJ (mensal, a partir de jan/2008); preços FIPE-ZAP SP (mensal, a partir de jan/2008); preços IVG-R (mensal, a partir de março de 2001); e preços Jornal O Globo para Rio de Janeiro (mensal, a partir de jan/1999).

\section{Regressão FIPE-ZAP para o Rio de Janeiro}

Inicialmente, aplica-se o teste de Raiz Unitária Dick-Fuller Aumentado (ADF) para se identificar a ordem de integração das variáveis. O teste de cointegração da variável preço com as variáveis explicativas resulta na verificação de não relação de cointegração de longo prazo. Em outras palavras, os fundamentos do preço (medidos sob diversos prismas na seleção de variáveis independentes) não parecem explicar o comportamento de longo prazo do preço. A seguir, aplica-se a transformação de logaritmo a todas as variáveis em nível ou em formato índice. Em seguida, aplica-se o operador de $1^{\text {a }}$ diferença para se obter séries estacionárias, nos casos de cointegração de ordem 1. 
A Tabela 1 apresenta o resultado do modelo base que mede efeitos contemporâneos no preço em $1^{a}$ diferença (com estatísticas $t$ ajustadas pelo procedimento HAC Newey-West):

Tabela 1

Regressão FIPE-ZAP RJ em Diferenças

\begin{tabular}{lcccc}
\hline Variável Independente & Coeficiente & Erro Padrão & t-Stat & P-valor \\
\hline DLM3_SPIB & $-0,569^{*}$ & 0,2096 & $-2,7171$ & 0,0085 \\
DLM3_REAL & $0,667^{*}$ & 0,2441 & 2,7314 & 0,0082 \\
DLIPCA & $-1,276$ & 0,7045 & $-1,8117$ & 0,0749 \\
DLALUG & $0,309^{*}$ & 0,0658 & 4,6880 & 0,0000 \\
_LSELIC & $0,016^{* *}$ & 0,0070 & 2,3340 & 0,0229 \\
DLCAMB & $-0,043$ & 0,0279 & $-1,5274$ & 0,1317 \\
_LLANC_SA & $0,002^{* *}$ & 0,0009 & 2,0034 & 0,0495 \\
C & $-0,043$ & 0,0218 & $-1,9658$ & 0,0538 \\
@ TREND & 0,000 & 0,0001 & 1,5882 & 0,1173 \\
R2 ajustado & 0,38 & & & \\
\hline
\end{tabular}

Nota. A variável dependente é o Dif-Log do preço real de imóveis FIPE-ZAP RJ. As estatísticas t são ajustadas segundo o procedimento HAC Newey-West.

(*) indica significância a 1\%,(**) indicam significância a $5 \%$.

Apesar de um poder explicativo, medido pelo R2, baixo, as variáveis apresentam efeito significativo na variação do preço, à exceção do IPCA e da taxa de câmbio ${ }^{(6)}$. Os resultados confirmam a expectativa de que uma ampliação da liquidez (DLM3_REAL) tenha o efeito de elevar o preço de imóveis. O M3 mede a liquidez geral da economia. A ampliação na oferta de crédito vem sendo o principal motor do aumento do M3. Entretanto, a relação M3/PIB (DLM3_SPIB) apresenta sinal inverso ao esperado. O preço do aluguel (DLALUG) confirma a hipótese econômica, de que é diretamente proporcional ao preço do imóvel, tudo o mais constante. O sinal do coeficiente da SELIC (_LSELIC) obtido não confirma a teoria econômica, de que um aumento nas taxas de juros produz redução no preço de imóveis. Isso pode ter ocorrido em razão de: (a) defasagem temporal nos efeitos, (b) janela de tempo insuficiente para uma adequada estimação. A quantidade de lançamentos no mês (_LLANC_SA) apresenta sinal contrário ao esperado, pois um aumento na oferta levaria a um decréscimo no preço. Entretanto, como o preço médio dos anúncios é largamente determinado pelo estoque existente de imóveis (e não pelo pequeno acréscimo mensal ao estoque), essa variável pode não ser adequada para se fazer esse tipo de inferência.

A taxa de câmbio (DLCAMB) confirma a teoria econômica, ou seja, a elevação do preço do dólar tende a elevar o preço dos imóveis em reais, e o sinal do IPCA (DLIPCA) é negativo e justificado na teoria econômica por 2 linhas de argumentação em favor de um efeito negativo do índice de preços gerais em imóveis. Acredita-se que o aumento do índice geral de preços tenha o efeito de reduzir o preço de imóveis, na medida em que o encarecimento do preço dos demais produtos poderia reduzir a disponibilidade de recursos para compra de imóveis. Uma outra linha de raciocínio é que um aumento na taxa de inflação tem o condão, no curto prazo, de reduzir o valor real do imóvel (supondo-se um atraso no ajuste dos preços nominais).

Como conclusão, os sinais dos coeficientes confirmam o que é normalmente esperado, à luz da teoria econômica, para 4 variáveis independentes (Preço do aluguel, IPCA, Taxa de câmbio, M3 real). Apesar da literatura apontar a renda como uma das variáveis fundamentais mais importantes para explicar o preço de imóveis, essa variável não apresenta coeficiente significativo em seu efeito contemporâneo no preço. 
Dentro do grau de liberdade que as regressões múltiplas permitem, passa-se então a testar lags das variáveis explicativas. Nesse contexto, busca-se reintroduzir variáveis que haviam sido descartadas na etapa anterior (agora, tomando-se lags), bem como reposicionar variáveis já utilizadas, mas, desta vez, com lags. A variável renda foi introduzida, e mostra a melhor performance no nono lag (com pvalor $=5,5 \%)$. O novo modelo ajustado encontra-se na Tabela 2 .

Tabela 2

Regressão FIPE-ZAP RJ em Diferenças com Lags

\begin{tabular}{lcccc}
\hline Variável Independente & Coeficiente & Erro Padrão & t-Stat & P-valor \\
\hline DLALUG & $0,277^{*}$ & 0,0778 & 3,5586 & 0,0008 \\
DLIPCA & $-1,088^{*}$ & 0,4015 & $-2,7090$ & 0,0089 \\
DLM3_SPIB & $-0,563^{*}$ & 0,1114 & $-5,0570$ & 0,0000 \\
DLM3_REAL & $0,868^{*}$ & 0,1708 & 5,0800 & 0,0000 \\
C & $0,103^{*}$ & 0,0225 & 4,5528 & 0,0000 \\
_LSELIC(-10) & $-0,015^{*}$ & 0,0041 & $-3,6113$ & 0,0007 \\
LVENDACC_SA(-9) & $-0,012^{*}$ & 0,0033 & $-3,5001$ & 0,0009 \\
DLDESEMP_SA(-5) & $-0,058^{*}$ & 0,0138 & $-4,2299$ & 0,0001 \\
DLRENDA(-9) & 0,068 & 0,0348 & 1,9643 & 0,0545 \\
R2 ajustado & 0,64 & & & \\
\hline
\end{tabular}

Nota. A variável dependente é o Dif-Log do preço real de imóveis FIPE-ZAP RJ. As estatísticas t são ajustadas segundo o procedimento HAC Newey-West.

(*) indica significância a 1\%,(**) indica significância a 5\%.

Nesse novo arranjo, a variável que media a quantidade de lançamentos no RJ perdeu relevância. $\mathrm{O}$ ajuste do modelo medido pelo R2 é de 64\%. Vendas de material de construção civil (LVENDACC_SA) é a primeira variável introduzida em lag e que não estava no modelo anterior. Essa variável é uma proxy para o grau de aquecimento da indústria e uma sinalização de aquecimento futuro dos lançamentos, aparecendo com efeito significativo em seu $9^{\circ} \mathrm{lag}$, com o sinal de acordo com o esperado (aumento da oferta tende a reduzir preço). A taxa de desemprego (DLDESEMP_SA) é a segunda variável que aparece com poder de prever alterações na variação do preço real de imóveis com 5 meses de antecedência. O sinal é o esperado, pois aumento do desemprego reduz a demanda, o que leva a, tudo o mais constante, a uma redução no preço de imóveis. Por fim, a renda é a última variável que aparece nesse modelo. $\mathrm{O}$ aumento de renda produz efeito marginalmente significativo e positivo na variação do preço 9 meses à frente.

A existência de lags da variável dependente com significância estatística pode ser encarado como indício de um viés comportamental conhecido como backwards looking. Basicamente, significa os formadores de preço valerem-se do preço passado para precificar o preço futuro, a despeito da Teoria Econômica Clássica (o preço do ativo depende apenas da perspectiva de geração futura de fluxo de caixa). Introduzindo-se o $1^{\circ}$ lag do preço de imóveis, chega-se ao resultado da Tabela 3. 
Tabela 3

\section{Regressão FIPE-ZAP RJ em Diferenças com 1 Defasagem da Variável Dependente}

\begin{tabular}{lcccc}
\hline Variável Independente & Coeficiente & Erro Padrão & t-Stat & P-valor \\
\hline DLALUG & 0,093 & 0,0602 & 1,5487 & 0,1272 \\
DLIPCA & $-0,539^{* *}$ & 0,2619 & $-2,0590$ & 0,0442 \\
DLM3_SPIB & $-0,144$ & 0,1096 & $-1,3098$ & 0,1957 \\
DLM3_REAL & 0,163 & 0,1244 & 1,3129 & 0,1947 \\
C & $0,035^{*}$ & 0,0123 & 2,8734 & 0,0058 \\
_LSELIC(-10) & $-0,004$ & 0,0026 & $-1,6907$ & 0,0966 \\
LVENDACC_SA(-9) & $-0,004^{* *}$ & 0,0017 & $-2,5504$ & 0,0136 \\
DLDESEMP_SA(-5) & $-0,011$ & 0,0119 & $-0,9648$ & 0,3388 \\
DLRENDA(-9) & $-0,001$ & 0,0181 & $-0,0371$ & 0,9705 \\
DLPRICE_REAL(-1) & $0,757^{*}$ & 0,0846 & 8,9404 & 0,0000 \\
\hline
\end{tabular}

R2 ajustado 0,88

Nota. A variável dependente é o Dif-Log do preço real de imóveis FIPE-ZAP RJ. As estatísticas t são ajustadas segundo o procedimento HAC Newey-West.

(*) indica significância a 1\%, (**) indica significância a 5\%.

O efeito do $1^{\circ}$ lag da variável dependente no modelo é ampliar o R2 para $88 \%$, e reduzir a significância de diversas outras variáveis explicativas. Pode-se concluir, pelo magnitude do coeficiente, que o preço do período anterior (DLPRICE_REAL) influencia enormemente a variável dependente e que a contribuição de todas as variáveis explicativas torna-se insignificante (à exceção do IPCA e da venda de material de construção civil no Rio de Janeiro no $9^{\circ} \mathrm{lag}$ ).

A seguir, adotam-se duas séries contendo índices que medem a confiança do consumidor: INEC (Índice Nacional de Expectativas do Consumidor, medido pela CNI) e o ICC-FGV (Índice de Confiança do Consumidor). Ambos contêm informações agregadas para o país como um todo. Os resultados indicam que o INEC não apresenta efeito significativo e que o ICC-FGV apresenta efeito marginalmente significativo (apenas a $10 \%$ ) em seu $11^{\circ}$ lag.

A introdução do Índice Bovespa mensal resulta em efeito significativo em seu $8^{\circ} \mathrm{lag}$. Em outras palavras, a variação mensal do IBOVESPA tem força explicativa sobre a variação do preço de 8 meses à frente. Além disso, adota-se dummies para teste do modelo básico. A dummy que mede o entusiasmo internacional com o Brasil apresenta o melhor desempenho: mostra significância elevada, com um $t$-stat de 6,8. Com isso, o R2 da regressão passa de 37\% para 73\%. Uma explicação possível, e, considerando efeitos causais anteriores, é a de que o lançamento do Programa Minha Casa Minha Vida, em março de 2009, e o aumento do limite para uso do FGTS para R $\$ 500$ mil, em março de 2009, contribuem de forma defasada para o ciclo de elevação dos preços.

\section{Regressão FIPE-ZAP para São Paulo}

A Tabela 4 apresenta o modelo base para o preço real em São Paulo. 
Tabela 4

Regressão FIPE-ZAP SP em Diferenças

\begin{tabular}{lcccc}
\hline Variável Independente & Coeficiente & Erro Padrão & $\boldsymbol{t}$-Stat & P-valor \\
\hline DLM3_REAL & $0,315^{*}$ & 0,0800 & 3,9326 & 0,0002 \\
DLM3_SPIB & $-0,180^{*}$ & 0,0722 & $-2,4972$ & 0,0150 \\
DLCAMB & $-0,018$ & 0,0122 & $-1,4692$ & 0,1465 \\
_LSELIC & 0,007 & 0,0046 & 1,5045 & 0,1371 \\
DLIPCA & $0,457^{* *}$ & 0,2149 & 2,1288 & 0,0370 \\
C & $-0,001$ & 0,0114 & $-0,1047$ & 0,9169 \\
@ TREND & $0,000^{* *}$ & 0,0000 & $-2,1545$ & 0,0348 \\
\hline R2 ajustado & 0,49 & & & \\
\hline
\end{tabular}

Nota. A variável dependente é o Dif-Log do preço real de imóveis FIPE-ZAP SP. As estatísticas t são ajustadas segundo o procedimento HAC Newey-West.

(*) indica significância a 1\%,(**) indica significância a 5\%.

Observa-se que 3 variáveis do modelo do RJ não apresentam resultado relevante para SP (lançamentos mensais, SELIC e índice de aluguel FIPE-ZAP). Apesar disso, os sinais dos coeficientes são idênticos aos observados no modelo do RJ, à exceção do IPCA, que aparece aqui com sinal positivo. A inclusão de lags de outras variáveis explicativas resulta no modelo da Tabela 5. Neste caso, a única alteração significativa é a inclusão da SELIC em seu $11^{\circ} \mathrm{lag}$, com coeficiente significativo e sinal conforme esperado.

Tabela 5

Regressão FIPE-ZAP SP em Diferenças com Lags

\begin{tabular}{lcccc}
\hline Variável Independente & Coeficiente & Erro Padrão & $\boldsymbol{t}$-Stat & P-valor \\
\hline DLM3_REAL & $0,274^{*}$ & 0,0763 & 3,5850 & 0,0007 \\
DLM3_SPIB & $-0,121^{* *}$ & 0,0504 & $-2,4020$ & 0,0195 \\
DLIPCA & $0,572^{*}$ & 0,1957 & 2,9218 & 0,0050 \\
C & $0,035^{*}$ & 0,0070 & 4,9012 & 0,0000 \\
@ TREND & $0,000^{*}$ & 0,0000 & $-7,1626$ & 0,0000 \\
_LSELIC(-11) & $-0,006^{* *}$ & 0,0025 & $-2,4531$ & 0,0172 \\
R2 ajustado & 0,58 & & & \\
\hline
\end{tabular}

Nota. A variável dependente é o Dif-Log do preço real de imóveis FIPE-ZAP SP. As estatísticas t são ajustadas segundo o procedimento HAC Newey-West.

(*) indica significância a 1\%, (**) indica significância a 5\%.

Introduzindo-se o $1^{\circ}$ lag do preço de imóveis na especificação base em lags, chega-se ao resultado da Tabela 6. 
Tabela 6

Regressão FIPE-ZAP SP em Diferenças e Variável Dependente com 1 Defasagem

\begin{tabular}{lcccc}
\hline Variável Independente & Coeficiente & Erro Padrão & $\boldsymbol{t}$-Stat & P-valor \\
\hline DLM3_REAL & $0,165^{*}$ & 0,0443 & 3,7190 & 0,0004 \\
DLM3_SPIB & $-0,100^{* *}$ & 0,0398 & $-2,5220$ & 0,0141 \\
DLCAMB & $-0,008$ & 0,0079 & $-1,0804$ & 0,2840 \\
_LSELIC & 0,002 & 0,0019 & 1,0256 & 0,3089 \\
DLIPCA & $0,316^{* *}$ & 0,1242 & 2,5425 & 0,0134 \\
C & 0,001 & 0,0049 & 0,1279 & 0,8986 \\
@TREND & $0,000^{* *}$ & 0,0000 & $-2,4019$ & 0,0192 \\
DLPRECO_SP(-1) & $0,617^{*}$ & 0,0861 & 7,1730 & 0,0000 \\
\hline R2 ajustado & 0,76 & & & \\
\hline
\end{tabular}

Nota. A variável dependente é o Dif-Log do preço real de imóveis FIPE-ZAP SP. As estatísticas t são ajustadas segundo o procedimento HAC Newey-West.

(*) indica significância a 1\%,(**) indica significância a 5\%.

A exemplo do que ocorreu no modelo do RJ, a inclusão de uma defasagem da variável dependente tende a reduzir a significância das variáveis explicativas do modelo e aumentar significativamente o R2. Além dos 2 índices que medem a confiança do consumidor utilizados no modelo do RJ, adota-se um indicador específico para Região Metropolitana de SP, o IEC, medido pela Fecomércio-SP. Este último é o único que mostra significância a $1 \% \mathrm{em}$ seu $10^{\circ} \mathrm{lag}$. A introdução do Índice Bovespa resulta em efeito positivo e significativo em seu $1^{\circ} \mathrm{lag}$, mas sem magnitude e relevância no R2.

A exemplo do modelo do RJ, a introdução da dummy que mede o entusiasmo internacional com o Brasil mostra significância a $1 \%$ com alteração no R2 de $49 \%$ para $63 \%$. Como o comportamento do preço em SP, medido pelo FIPE-ZAP, foi menos explosivo do que no Rio de Janeiro, é esperado que as dummies comportamentais produzam efeito menor sobre o resultado geral da regressão.

\section{Regressão IVG-R}

Inicialmente, constata-se que as séries de interesse são integradas de ordem 1. A Tabela 7 apresenta o modelo de cointegração da série.

Tabela 7

Regressão IVG-R em Nível (Variável Dependente: Preço de Imóveis em Logaritmo)

\begin{tabular}{lcccc}
\hline Variável Independente & Coeficiente & Erro Padrão & $\boldsymbol{t}$-Stat & P-valor \\
\hline LM3 & $0,663^{*}$ & 0,0199 & 33,3163 & 0,0000 \\
LRENDA_BR & $2,403^{*}$ & 0,1784 & 13,4661 & 0,0000 \\
LVOL_CC_SA & $0,355^{* *}$ & 0,1584 & 2,2438 & 0,0263 \\
CAMBIO & 0,089 & 0,0475 & 1,8786 & 0,0622 \\
C & $-24,146^{*}$ & 1,7679 & $-13,6580$ & 0,0000 \\
\hline R2 ajustado & 0,98 & & &
\end{tabular}

Nota. A variável dependente é o Log do IVG-R deflacionado pelo IPCA. As estatísticas t são ajustadas segundo o procedimento HAC Newey-West.

$(*)$ indica significância a $1 \%,(* *)$ indica significância a $5 \%$. 
Os resíduos da regressão são estacionários, o que indica a possibilidade da regressão representar uma relação de cointegração entre série integradas de $1^{\mathrm{a}}$ ordem. O M3 real dessazonalizado (LM3) é o principal fator explicativo do modelo com sinal correspondente ao que se espera pela teoria econômica. A renda real (LRENDA_BR) também se mostra significativa e com o sinal esperado. O volume da produção da indústria de construção civil (LVOL_CC_SA), que tenderia a ampliar a oferta e com isso baixar o preço, aparece com o sinal contrário ao esperado, e o câmbio apresenta significância apenas marginal. Verifica-se ainda, a presença de vetores de cointegração por meio do teste de Engle-Granger, que acusa a presença de relação de cointegração tendo o preço IVG-R como variável dependente, e Johansen, que acusa a presença de 2 vetores de cointegração. Por fim, constata-se a estacionariedade dos resíduos da regressão das variáveis em nível, pré-condição para que exista uma relação de cointegração.

Por conta desses resultados, aplica-se a metodologia dos modelos de correção de erros, que consiste em extrair a relação de longo prazo entre as variáveis de interesse (em nível) e montar a equação de curto prazo de diferenças da variáveis dependentes em função de diferenças defasadas dela mesma (e das variáveis independentes) e um termo de correção de erro (o resíduo com 1 defasagem da regressão de cointegração). A Tabela 8 apresenta os resultados.

Tabela 8

\section{Regressão IVG-R em Modelo de Correção de Erro (Variável Dependente: IVG-R Deflacionado em Dif-Log)}

\begin{tabular}{lcccc}
\hline Variável Independente & Coeficiente & Erro Padrão & $\boldsymbol{t}$-Stat & P-valor \\
\hline DLP_IVG_REAL(-1) & $0,813^{*}$ & 0,0562 & 14,4655 & 0,0000 \\
DLP_IVG_REAL(-2) & $0,124^{* *}$ & 0,0611 & 2,0218 & 0,0450 \\
ECT(-1) & $-0,005$ & 0,0032 & $-1,6995$ & 0,0913 \\
C & 0,001 & 0,0004 & 1,6672 & 0,0976 \\
DLRENDA_BR(-1) & $-0,047$ & 0,0250 & $-1,8694$ & 0,0636 \\
DCAMBIO(-2) & $-0,014^{*}$ & 0,0039 & $-3,6159$ & 0,0004 \\
DCAMBIO(-1) & $-0,004$ & 0,0028 & $-1,3645$ & 0,1745 \\
\hline R2 ajustado & 0,90 & & & \\
\hline
\end{tabular}

Nota. A variável dependente é o Dif-Log do IVG-R deflacionado pelo IPCA. As estatísticas t são ajustadas segundo o procedimento HAC Newey-West.

(*) indica significância a 1\%, (**) indica significância a 5\%.

Testam-se os efeitos de diferenças até 2 lags, até se obter o melhor desempenho para o termo de correção de erros (ECT). Nota-se que o movimento de curto prazo do preço possui características de fortemente autocorrelacionado, influenciado negativamente por uma variação de renda no período anterior (contrário a intuição econômica), influenciado negativamente por uma variação da taxa de câmbio de 2 períodos anteriores e componente de ajuste a fundamentos de longo prazo (ECT) com baixa significância, o que sugere um comportamento de evolução de preços potencialmente descolado de fundamentos.

A série do INEC, com data base em janeiro de 2001, é utilizada na regressão de curto prazo do modelo de correção de erros e mostra-se significativa positiva sobre a variação do preço em seu $6^{\circ}$ lag. O Índice Bovespa resulta em efeito significativo em seu $2^{\circ}$ lag e sugere o efeito substituição mencionado em Agnello e Schuknecht (2011) sobre o mercado imobiliário nos EUA e na Europa. O aumento no preço por imóveis é precedido por uma queda no mercado de capitais. Por fim, a introdução das dummies na equação de curto prazo do modelo de correção de erros não indica efeito significativo. Esse resultado sugere que, em razão da dominância do poder explicativo do $1^{\circ}$ lag do preço em diferenças, a força explicativa de variáveis adicionadas ao modelo fica eclipsada. 
Passa-se então ao modelo de longo prazo com duas dummies. A primeira é a dummy relacionada a inovações: (a) lei patrimônio de afetação e alienação fiduciária em agosto de 2008; (b) resolução CMN elevando volume de recursos direcionados ao crédito habitacional de abril de 2005; e (c) resolução BACEN ampliando recursos disponíveis ao crédito imobiliário de fevereiro de 2006. A segunda é a dummy de condições de financiamento: (a) ampliação do prazo máximo de financiamento de 20 para 30 anos de setembro de 2007; e (b) aumentos do valor referência para uso do FGTS, em março de 2009, de $\mathrm{R} \$ 350$ mil para $\mathrm{R} \$ 500 \mathrm{mil}$, e em setembro de 2013, para $\mathrm{R} \$ 750$ mil.

A performance dessas novas dummies, juntamente com a dummy que mede o entusiasmo internacional com o Brasil (D_hype), apresenta resultados significativos, conforme Tabela 9.

Tabela 9

Regressão IVG-R em Nível com Dummies (Variável Dependente: IVG-R Deflacionado em Log)

\begin{tabular}{lcccc}
\hline Variável Independente & Coeficiente & Erro Padrão & $\boldsymbol{t}$-Stat & P-valor \\
\hline LM3 & $0,800^{*}$ & 0,0327 & 24,4959 & 0,0000 \\
LRENDA_BR & $1,702^{*}$ & 0,0838 & 20,3248 & 0,0000 \\
LVOL_CC_SA & $0,196^{* *}$ & 0,0823 & 2,3769 & 0,0187 \\
CAMBIO & $-0,054^{*}$ & 0,0114 & $-4,6905$ & 0,0000 \\
C & $-19,627^{*}$ & 0,8394 & $-23,3827$ & 0,0000 \\
D_HYPE & $0,060^{*}$ & 0,0193 & 3,1145 & 0,0022 \\
D_INSTITUCIONAL & $-0,117^{*}$ & 0,0100 & $-11,6637$ & 0,0000 \\
D_FGTS_LIMITE & $0,058^{* *}$ & 0,0256 & 2,2795 & 0,0241 \\
D_PRAZO_30ANOS & 0,044 & 0,0228 & 1,9225 & 0,0565 \\
\hline R2 ajustado & 0,99 & & & \\
\hline
\end{tabular}

Nota. A variável dependente é o Log do IVG-R deflacionado pelo IPCA. As estatísticas t são ajustadas segundo o procedimento HAC Newey-West.

(*) indica significância a 1\%,(**) indica significância a 5\%.

Com relação às dummies de inovação, o sinal do efeito das mudanças legais (D_INSTITUCIONAL) no preço foi negativo, ou seja, as inovações institucionais contribuem para reduzir o preço. As dummies que medem melhorias nas condições financiamento (D_FGTS_LIMITE e D_PRAZO_30ANOS) e o grau de entusiasmo com o Brasil (D_HYPE) apresentam sinal positivo.

\section{Regressão de Preços de O Globo para Rio de Janeiro}

A Tabela 10 apresenta os resultados da regressão com dados de preços do Rio de Janeiro retirados do caderno Morar Bem do Jornal O Globo. A série de preços (em log) do Índice Composto Globo (ICG) é estacionária em sua $1^{\text {a }}$ diferença (a 1\%). Isso viabiliza a aplicação de metodologia de Modelos de Correção de Erro. 
Tabela 10

Regressão Índice Composto Globo(ICG) em Nível (Variável Dependente: ICG Deflacionado em $\log )$

\begin{tabular}{lcccc}
\hline Variável Independente & Coeficiente & Erro Padrão & $\boldsymbol{t}$-Stat & P-valor \\
\hline LM3 & $0,750^{*}$ & 0,0507 & 14,7932 & 0,0000 \\
LRENDA_RJ & $2,029^{*}$ & 0,2038 & 9,9525 & 0,0000 \\
LVOL_CC_SA & $-0,807^{* *}$ & 0,3618 & $-2,2300$ & 0,0270 \\
CAMBIO & $0,196^{*}$ & 0,0706 & 2,7768 & 0,0061 \\
SELIC_AA & $0,017^{* *}$ & 0,0082 & 2,1009 & 0,0371 \\
C & $-17,417^{*}$ & 3,1618 & $-5,5088$ & 0,0000 \\
\hline R2 ajustado & 0,90 & & & \\
\hline
\end{tabular}

Nota. A variável dependente é o Log do ICG deflacionado pelo IPCA. As estatísticas t são ajustadas segundo o procedimento HAC Newey-West.

(*) indica significância a 1\%,(**) indica significância a 5\%.

O teste de cointegração Engle-Granger aponta a presença de 1 relação de cointegração na variável dependente preço de imóveis, e o teste de cointegração Johansen aponta a presença de 1 vetor de cointegração. Já a estatística autovalor não indica a presença de cointegração.

Com esses resultados, sugere-se a existência de uma relação de cointegração entre as variáveis, tendo o preço como dependente. Por fim, a estacionariedade dos resíduos da regressão em nível a $1 \%$ confirmam a possibilidade de a regressão em níveis representar uma relação de cointegração de longo prazo.

A partir da regressão em níveis, aplica-se a metodologia do modelo correção de erros. Após ajustes, chega-se ao modelo de curto prazo da Tabela 11.

Tabela 11

Regressão ICG em Modelo de Correção de Erro (Variável Dependente: ICG Deflacionado em DifLog)

\begin{tabular}{lcccc}
\hline Variável Independente & Coeficiente & Erro Padrão & $\boldsymbol{t}$-Stat & P-valor \\
\hline DLP_GLOBO(-1) & $0,544^{*}$ & 0,0925 & 5,8749 & 0,0000 \\
ECT_GLOBO(-1) & $-0,023^{* *}$ & 0,0112 & $-2,0498$ & 0,0419 \\
C & 0,003 & 0,0029 & 1,1419 & 0,2551 \\
DLRENDA_RJ(-1) & 0,075 & 0,0847 & 0,8846 & 0,3776 \\
DSELIC(-1) & $-0,002^{*}$ & 0,0006 & $-3,2451$ & 0,0014 \\
DLVOL_CC_SA(-2) & 0,033 & 0,0454 & 0,7356 & 0,4630 \\
DCAMBIO(-2) & $-0,007$ & 0,0116 & $-0,6099$ & 0,5428 \\
DLM3(-2) & 0,104 & 0,2201 & 0,4729 & 0,6369 \\
\hline R2 ajustado & 0,29 & & & \\
\hline
\end{tabular}

Nota. A variável dependente é o Dif-Log do ICG deflacionado pelo IPCA. As estatísticas t são ajustadas segundo o procedimento HAC Newey-West.

(*) indica significância a 1\%,(**) indica significância a 5\%. 
Apesar de haver diversas variáveis com contribuições não significativas, apresenta-se essa especificação para avaliar o efeito do termo de correção de erro (ECT_GLOBO (-1)). Apesar do ajuste geral do modelo ser baixo, o termo de correção de erro, que representa o efeito de correção para fundamentos da trajetória do preço, mostra-se significativo a 5\%, e com o sinal esperado. No entanto, a força (velocidade) da correção é fraca. Após um choque, o preço tende a reverter ao que é determinado pela relação de cointegração (fundamentos) com uma velocidade de $2,3 \%$ por período - o que implica em uma reversão completa em 2,5 anos, aproximadamente. Prevalece, na configuração da equação de curto prazo, a força do componente autocorrelacionado (defasagem da $1^{\text {a }}$ diferença do preço).

O melhor ajuste para índices é do INEC no efeito de seu $8^{\circ}$ lag sobre a variação do preço, em que o coeficiente mostra-se significativo a 5\%, e com sinal conforme o esperado. A taxa de variação mensal do Índice Bovespa não é significativa na regressão de curto prazo, e a introdução das dummies na equação de curto prazo do modelo de correção de erros não indica efeito significativo.

No modelo de longo prazo, obtém-se resultados positivos individualmente com dummy da olimpíada (aumenta o preço), dummy da minha casa minha vida (aumenta o preço), dummy do prazo de 30 anos (reduz o preço), dummy da alteração do limite do FGTS (aumenta preço) e dummy de inovação (efeito negativo no preço). A melhor performance foi obtida com a dummy de inovação, que aumenta o R2 do modelo de longo prazo de $90 \%$ para $94 \%$. O resultado sugere que o efeito negativo no preço por conta das inovações institucionais deva-se ao efeito de medidas regulatórias positivas para o mercado, facilitando as condições para se ampliar a oferta. É importante destacar, que de modo genérico, há o entendimento de que a oferta é a variável mais importante para a formação de preços, e que a estrutura de formação de preços pode seguir lógicas nem sempre explicadas pelas variáveis escolhidas no estudo ou adequadas para algum outro período de estudo.

\section{Conclusão}

O objetivo do trabalho é verificar se há um fator de natureza comportamental ou econômico que possa ter influenciado o movimento de preços na última década dos mercados do Rio de Janeiro e de São Paulo. Além disso, o trabalho monta uma série, denominada de Índice Composto Globo, para comparação com as demais séries do mercado imobiliário brasileiro. O resultado referente a componentes econômicas sugere que há força explicativa nos determinantes de preço de longo prazo, sobretudo do agregado monetário M3 a valores reais, o que indica um ciclo de expansão do mercado puxado pela ampliação do crédito.

As regressões de curto prazo sugerem que o preço de imóveis é influenciado por determinantes não usuais à luz da teoria econômica tradicional, como a variação do preço no mês anterior, uma medida do grau de expectativas da economia defasado e a performance defasada da Bolsa. Além disso, fatores comportamentais, como o entusiasmo internacional com o Brasil, e resultante de inovações, também mostram efeito expressivo sobre o comportamento do preço de curto prazo.

Diferente de outros trabalhos, a renda real das famílias não apresenta poder explicativo significante nas regressões com dados do FIPE-ZAP. No entanto, em séries mais longas, como IVG-R e Índice Composto Globo, a renda real aparece como fator significante para explicar o movimento de preços de longo prazo.

As equações de curto prazo com dados do IVG-R e Índice Composto Globo indicam que a variação do preço é regida, sobretudo, pela variação do preço no período anterior, o que confirma o aspecto fortemente autocorrelacionado do preço de imóveis. Isso também confirma a hipótese do backwards looking, ou seja, da forte autocorrelação com a primeira defasagem, fato estilizado acerca dos mercados imobiliários. Os índices de confiança do consumidor mostram efeitos pouco significativos em todos os modelos. Com relação ao Ibovespa, busca-se medir a existência do chamado efeito 
substituição. Os resultados sugerem efeitos de substituição significativos na variação do preço apenas no IVG-R.

Em relação às dummies, a dummy que mede o entusiasmo internacional com o Brasil apresenta desempenho satisfatório em todos os modelos, tendo efeito positivo sobre o preço. A dummy de inovação também apresenta resultado significativo, mas com efeito negativo sobre o preço. O resultado sugere que, por capturar algumas mudanças legais que melhoram a segurança jurídica dos empreendimentos (alienação fiduciária, lei das incorporações), o efeito resultante das inovações institucionais foi de ampliar a oferta e forçar a queda dos preços.

É importante destacar, que de modo genérico, há o entendimento de que a oferta é a variável mais importante para a formação de preços, e que a estrutura de formação de preços pode seguir lógicas nem sempre explicadas pelas variáveis escolhidas no estudo ou inadequadas para algum outro período de estudo. Como sugestão de novos estudos, é interessante identificar as variações de preços de imóveis por regiões administrativas dos estados, principalmente levando-se em conta a visibilidade da região para o investidor estrangeiro.

\section{Notas}

${ }^{1}$ A série Índice Composto O Globo (ICG) foi obtida a partir dos principais bairros direcionadores do preço de anúncios em O Globo (Barra da Tijuca, Jacarepaguá, Copacabana, Botafogo, Tijuca, Méier e Ipanema). Da mesma forma que o atual FIPEZAP do Rio de Janeiro. O índice compilado a partir de O Globo reflete basicamente o preço de imóveis voltados às classes média e média-alta em bairros da Baixada de Jacarepaguá, Zona Norte e Zona Sul. O índice deixa de fora bairros populosos, porém inexpressivos no que tange à utilização do Jornal O Globo ou do Portal ZAP Imóveis, como Bangu, Campo Grande (e outros da Zona Oeste) e bairros da Zona Norte após o Méier e ao longo da Avenida Brasil. A metodologia está descrita no Apêndice.

${ }^{2}$ Dados obtidos nas páginas da Associação Brasileira das Entidades de Crédito Imobiliário e Poupança (ABECIP) e Câmara Brasileira da Indústria da Construção (CBIC).

${ }^{3}$ Associação de Dirigentes de Empresas do Mercado Imobiliário (ADEMI-RJ) para dados de lançamentos do Rio de Janeiro, e Sindicato das Empresas de Compra, Venda, Locação e Administração de Imóveis Residenciais e Comerciais de São Paulo (SECOVI-SP) para dados de São Paulo.

${ }^{4}$ A metodologia de construção da série inédita deste trabalho está no Apêndice.

${ }^{5}$ Vale registrar que as séries de preço do FIPE-ZAP e do Jornal O Globo são compostas por valores de anúncio. Os valores em que os imóveis são efetivamente negociados tendem a ser, naturalmente, inferiores aos valores anunciados. Não se encontrou registros confiáveis que pudessem suprir essa lacuna para os períodos de análise. A despeito dessa fragilidade da base de preços, acredita-se que os preços nominais (anunciados) e efetivos devem apresentar comportamento semelhante ao longo do tempo. Portanto, as variações e os pontos de inflexão tendem a ser os mesmos. Como nota complementar, especula-se que, em casos de estresse agudo de preços (como o momento pós 2009), o desconto típico necessário para fechamento de negócios pode ser maior do que em uma situação de regime do mercado - o que enfraquece, em alguma medida, a premissa de as séries de preços anunciados e preços efetivos sejam comoventes. Entretanto, a série de variação de garantias do BACEN (IVG-R) tende a acompanhar o preço real de venda de modo mais efetivo.

${ }^{6}$ A variável deficit habitacional é uma variável que pode influenciar de forma direta o preço dos imóveis. Entretanto, sua mensuração somente pode ser feita de forma indireta, isto é, por meio de proxies. Não é por outro motivo que se observam divergências significativas entre as diversas tentativas de quantificação do déficit atualmente existente.

\section{Referências}

Abelson, P., Joyeux, R., Milunovich, G., \& Chung, D. (2005). Explaining house prices in Australia: 1970-2003. Economic Record, 81(Suppl. 1), S96-S103. doi: 10.1111/j.1475-4932.2005.00243.x

Agnello, L., \& Schuknecht, L. (2011). Booms and busts in housing markets: determinants and implications. Journal of Housing Economics, 20(3), 171-190. doi:10.1016/j.jhe.2011.04.001 
Antipa, P., \& Lecat, R. (2009). The "housing bubble" and financial factors: insights from a structural model of the French and Spanish residential markets [Working Paper $\mathrm{n}^{\circ}$ 267]. Banque de France, Paris, France.

Associação de Dirigentes de Empresas do Mercado Imobiliário. (n.d.). Pesquisa ADEMI do mercado imobiliário. Rio de Janeiro. Recuperado de http://www.calepino.com.br/ademirio/pesquisa_cob/novapesquisa/

Bank for International Settlements. (2015, September 13). Residential property price statistics. Recuperado de http://www.bis.org/statistics/pp.htm

Carvalho, E. R. A. de (2012). Bolhas especulativas no preço de imóveis na cidade de São Paulo. Revista Paulista de Planejamento, 2(2), 66-80.

Case, K. E., \& Shiller, R. J. (1988). The behavior of home buyers in boom and post-boom markets. New England Economic Review, 11, 29-46.

Case, K. E., \& Shiller, R. J. (2003). Is there a bubble in the housing market? Brookings Papers on Economic Activity, (2), 299-362. doi: org/10.1353/eca.2004.0004

De Bondt, W. F. M., \& Thaler, R. (1985). Does the stock market overreact? Journal of Finance, 40(3), 793-805. doi: 10.1111/j.1540-6261.1985.tb05004.x

Fitch Ratings. (2012). Relatório da agência de classificação de risco Fitch sobre preço de imóveis residenciais em setembro de 2012. Recuperado de https://www.fitchratings.com.br/publications/5491

Gallin, J. (2008). The long-run relationship between house prices and rents. Real Estate Economics, 36(4), 635-658. doi: 10.1111/j.1540-6229.2008.00225.x

Glaeser, E. L., \& Gyourko, J. (2006). Housing dynamics [Working Paper $n^{\circ}$ 12787]. National Bureau of Economic Research, Cambridge, MA.

Glaeser, E. L., Gyourko, J., \& Saiz, A. (2008). Housing supply and housing bubbles. Journal of Urban Economics, 64(2), 198-217. doi: 10.1016/j.jue.2008.07.007

Goodman, A. C., \& Thibodeau, T. G. (2008). Where are the speculative bubbles in US housing markets? Journal of Housing Economics, 17(2), 117-137. doi: 10.1016/j.jhe.2007.12.001

Hott, C. (2012). The influence of herding behaviour on house prices. Journal of European Real Estate Research, 5(3), 177-198. doi: 10.1108/17539261211282046

Hwang, M., \& Quigley, J. (2006). Economic fundamentals in local housing markets: evidence from US metropolitan regions. Journal of Regional Science, 46(3), 425-453.

Krugman, P. (2009, September 2). How did economists get it so wrong? New York Times Magazine, 9, 36-46.

Marçal, E., Gala, P., \& Mori, R. (2012). Bolha no mercado imobiliário em São Paulo? Evidência baseada em testes econométricos [Working Paper $n^{\circ}$ 12]. Centro de Macroeconomia Aplicada, Fundação Getulio Vargas, São Paulo, SP, Brasil.

Mayer, C. (2011). Housing bubbles: a survey. Annual Review of Economics, 3(1), 559-577. doi: 10.1146/annurev.economics.012809.103822

Mayer, C., \& Sinai, T. (2007, September). Housing and behavioral finance. Proceedings of the Implications of Behavioral Economics on Economic Policy, Boston, MA, USA, 27. 
Mendonça, M., \& Sachsida, A. (2012). Existe bolha no mercado imobiliário brasileiro? [Texto para discussão, No 1762]. Brasília, DF: IPEA.

O Globo. (1998, novembro 1). Preço de imóveis no Rio de Janeiro. Classificados, Caderno Morar Bem, 2-10.

Oliveira, M. M. de, \& Almeida, A. C. L. (2014). Testing for rational speculative bubbles in the Brazilian residential real-estate market. Contemporary Studies in Economic and Financial Analysis, 96, 115. doi: 10.1108/S1569-375920140000096017

Shiller, R. (2007). Understanding recent trends in house prices and home ownership [Working Paper $\mathrm{n}^{\mathrm{o}}$ 13553]. National Bureau of Economic Research, Cambridge, MA.

The Economist. (2015, October 7). Global house prices. Recuperado de http://www.economist.com/blogs/dailychart/2011/11/global-house-prices

\section{Dados dos Autores}

Lincoln Brando

Av. Pres. Wilson, 118, Centro, 20030-020, Rio de Janeiro, RJ, Brasil. E-mail: lincoln.brando@ bndes.gov.br

Claudio Henrique Barbedo

Av. Pres. Wilson, 118, Centro, 20030-020, Rio de Janeiro, RJ, Brasil. E-mail: cbarbedo@ibmecrj.br 


\section{APÊNDICE}

\section{Índice Composto $\mathbf{O}$ Globo}

O índice de preços composto com dados do Jornal O Globo foi elaborado a partir de anúncios publicados no caderno Morar Bem, de O Globo, de novembro de 1998 a abril de 2014.

O critério para seleção dos bairros que compuseram o índice observou a composição típica dos anúncios de imóveis no Jornal, que basicamente são compostos por preços das seguintes regiões:

Zona Norte: com prevalência dos bairros que compõem a Grande Tijuca (Tijuca, Adaraí, Grajaú, Rio Comprido, etc.) e o Grande Méier (Méier, Cachambi, Engenho de Dentro, Encantado, etc.).

- Zona Sul: todos os bairros, mas com prevalência dos bairros com grande quantidade domicílios e oferta ao longo do tempo, como Copacabana e Botafogo

- Baixada de Jacarepaguá: Barra da Tijuca, Jacarepaguá e Recreio

O recorte de preços anunciados no Jornal O Globo, do mesmo modo que no portal FIPE-ZAP, é viesado para um certo perfil de imóvel voltado às Classes Média, Média-alta e Alta. Portanto, os 2 bairros com maior número de domicílios no Município do Rio de Janeiro (Campo Grande e Bangu), de acordo com o Censo de 2010, têm baixíssima representatividade na amostra de imóveis anunciados no período de análise.

Nessa ótica, e feita essa ressalva de que o preço médio de metro quadrado para imóveis no Rio de Janeiro, tanto do portal FIPE-ZAP, quanto o que se retira dos anúncios de O Globo, é fortemente viesado para um perfil de consumidor de maior poder aquisitivo, adotou-se a seguinte metodologia para se chegar a um índice composto de preços para o Rio de Janeiro.

1. selecionou-se os bairros mais representativos de cada uma das 3 regiões direcionadoras de preços (Zona Sul, Zona Norte e Baixada de Jacarepaguá);

2. fez-se um preço médio para cada uma das regiões (referência é para imóveis de 3 quartos);

3. obteve-se finalmente um preço médio composto para a cidade.

Os bairros selecionados para formação do índice de cada uma das três regiões na Baixada de Jacarepaguá são Barra da Tijuca e Jacarepaguá; na Zona Norte, Tijuca e Méier; e na Zona Sul, Copacabana, Botafogo e Ipanema.

A Figura A1 apresenta a curva do preço médio nominal por metro quadrado para os bairros selecionados. 


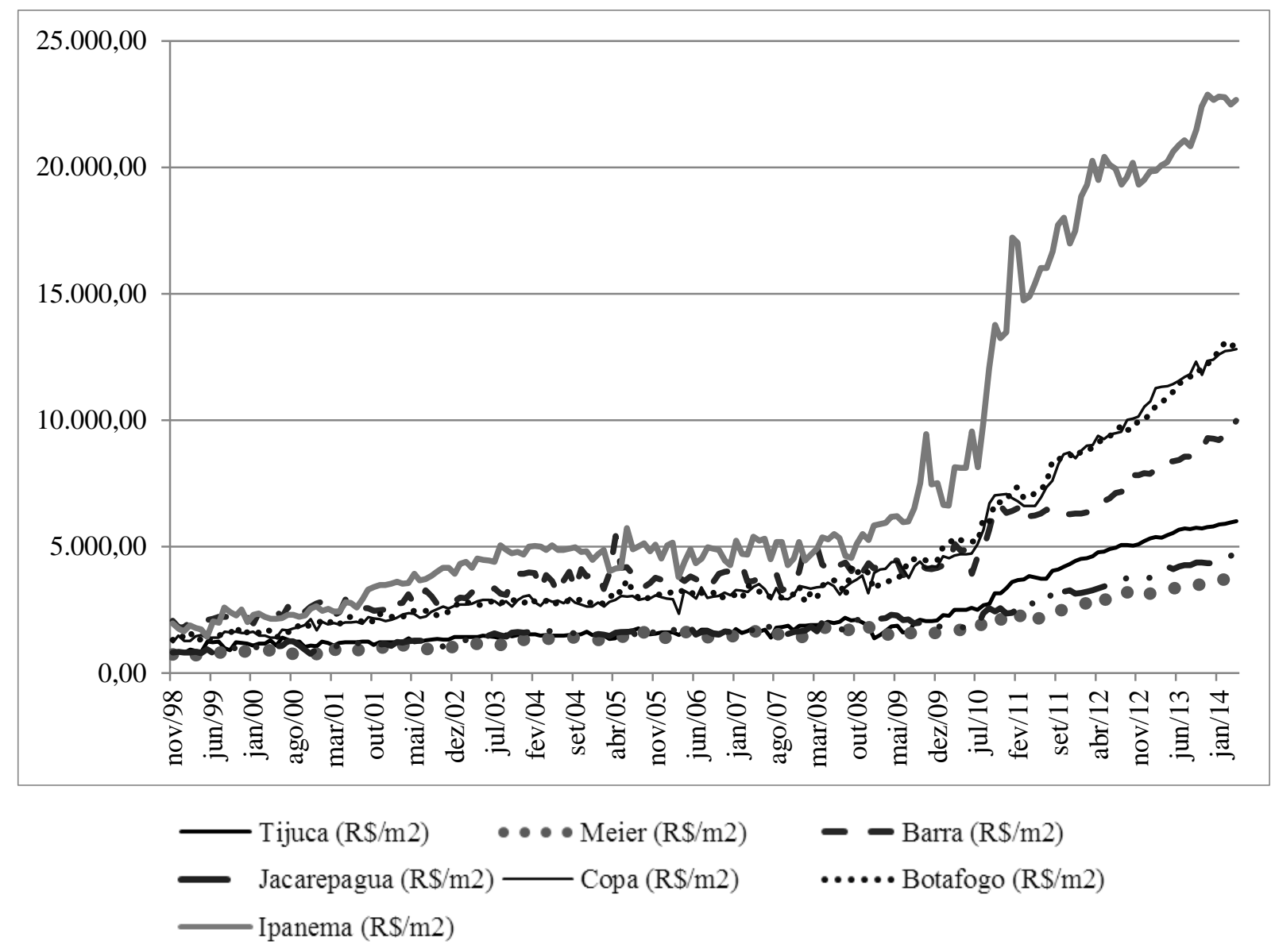

Figura A1. Preço Médio Nominal por Metro Quadrado - Bairros Selecionados

Para o cálculo dos preços médios:

- Preço médio Zona Sul: média aritmética dos preços de Copacabana, Botafogo (que, de certo modo, representam a Zona Sul média) e Ipanema (um representante dos bairros chamados triple A);

- Preço médio da Baixada de Jacarepaguá: média aritmética simples dos preços de Barra da Tijuca e de Jacarepaguá;

- Preço médio Zona Norte: média aritmética simples dos preços de Tijuca (representante da Zona Norte A) e Méier (representante da Zona Norte B).

Finalmente, o preço médio para o Rio de Janeiro foi obtido pela média aritmética simples dos preços da Baixada de Jacarepaguá, Zona Sul e Zona Norte. 